\section{Evaluation of Fungicides and Surfactants for Control of Fairy Rings Caused by Marasmius oreades (Bolt ex. Fr.) Fr.}

\author{
P.V. Blenis ${ }^{1}$, L.B. Nadeau ${ }^{2}$, N.R. Knowles ${ }^{3}$, and G. Logue ${ }^{4}$ \\ Department of Plant Science, University of Alberta, Edmonton, AB, Canada \\ T6G $2 P 5$
}

Additional index words. turfgrass, Poa pratensis, Festuca rubra, soil water, organosilicones, Sylgard, Silwet L-77

Abstract. Marasmius oreades, a causal agent of fairy rings, is one of the most important pathogens of turfgrass in the Great Plains region of North America. Following in vitro and greenhouse screening of surfactants and fungicides, two organosilicone surfactants, Silwet L-77 and Sylgard, together with the fungicide chlorothalonil, were evaluated in the field. Treatments were applied to healthy and infested turfgrass (Poa pratensis L., Festuca rubra L.) in either 1992, 1993, or in both years. Plots were sampled for grass production, canopy cover, mushroom production, grass chlorophyll content, soil water content, and phytotoxicity. Typically, there were no significant fungicide effects, fungicide by surfactant interactions or differences between Silwet L-77 and Sylgard. Relative to the water control, surfactants caused an approximate 3-fold increase in grass productivity on infested plots in the year of application. However, the difference in canopy cover between organosiliconetreated and control plots tended to be much less. Applying the surfactants to diseased plots in two successive years decreased the canopy cover but had no significant effect on grass production. Chlorophyll content tended to decrease in response to surfactants regardless of whether the turf was infested or healthy. Surfactants almost completely eliminated mushroom production and greatly reduced the occurrence of mycelium. Both organosilicones increased soil water content in infested areas; differences were detectable 2 years after application. Acute phytotoxicity from the surfactants was detected in infested but not in healthy plots. There was no direct evidence of chronic phytotoxicity. Organosilicone surfactants appear to have considerable potential for the management of fairy rings. Chemical names used: oxyalkylenemethylsiloxane (Silwet L-77); 2-(3hydroxypropyl)-heptamethyltrisiloxane (Sylgard); tetrachloroisopthalonitrile (chlorothalonil).

Fairy ring, caused by the fungus Marasmius oreades, is a common turfgrass disease in many parts of the world, especially on light soils with low moisture and fertility (Smith, 1978). Chemical control of $M$. oreades is difficult because the pathogen produces a water impervious layer that interferes with the movement of fungicide solutions in soil (Smith, 1980). If a method could be found for improving water movement through this water repel-

Received for publication 3 Jan. 1997. Accepted for publication 23 May 1997. Funding from the Alberta Agriculture Research Institute is gratefully acknowledged. We thank I. Duncan, G. McCoy, R. Berry, and $\mathrm{G}$. Schumaker for their technical assistance and the Dept. of Parks and Recreation, City of Edmonton, for their cooperation. The cost of publishing this paper was defrayed in part by the payment of page charges. Under postal regulations, this paper therefore must be hereby marked advertisement solely to indicate this fact.

'Current address: Dept. of Renewable Resources, Univ. of Alberta, Edmonton, AB, Canada, T6G $2 \mathrm{H} 1$.

${ }^{2}$ Current address: Northern Alberta Institute of Technology, Edmonton, AB, Canada, T5G 2R1.

${ }^{3}$ Current address: Dept. of Agricultural, Food and Nutritional Science, Univ. of Alberta, Edmonton, AB, Canada, T6G 2P5.

${ }^{4}$ Current address: School of Landscape Architecture, Univ, of Guelph, Guelph, ON, Canada, N1G $2 \mathrm{~W} 1$.

HorTSCIENCE, Vol. 32(6), OCTOBER 1997 oreades (UAMH 5503, UAMH 5751, UAMH 5754, and UAMH 6180 from the Univ. of Alberta Microfungus Collection and Herbarium) were tested at each concentration, with five replicate plates per combination of fungicide and concentration. Inoculum consisted of $1 \mathrm{~cm}$ diameter plugs of mycelium cut with a cork borer from the margin of colonies growing actively on potato dextrose agar. Colony diameter on fungicide-treated plates was recorded when the fungi on the control plates had grown across half of the plate. In the second experiment, the five fungicides (tribasic copper sulfate, copper oxychloride, anilazine, phenyl mercuric acetate, and thiram) that performed the best in the first experiment were retested against the same four isolates at concentrations of $0.3 \%, 0.7 \%, 1.5 \%, 3.0 \%$, $6.0 \%, 12.5 \%, 25.0 \%, 50.0 \%$, and $100 \%$ of their recommended rates, plus a control treatment without fungicide. Data from the initial fungicide screening were not analyzed statistically. For the second experiment, the average growth of the four isolates, at each combination of fungicide and concentration, was expressed as a percentage of their growth in the absence of a fungicide. Trends analysis was used to determine if average fungal growth and the linear trend in fungal growth with increasing fungicide concentrations varied with fungicide. The model was the following:

$$
Y_{i j}=\mu+F_{i}+e_{i j}
$$

where

$\mathrm{Y}=$ Dependent variable; either average fungal growth (as a percentage of the control) across all concentrations or the linear trend in fungal growth (as a percentage of the control) with increasing fungicide concentration.

$\mu=$ Overall mean.

$\mathrm{F}=$ Fungicide treatment

$\mathrm{e}=$ Experimental error.

Fungicide and surfactant effects on inlent zone, chemical control might be feasible. The organosilicone Silwet L-77, followed by Citowett and AgSurf, was the most effective of 13 surfactants screened for their ability to increase water uptake by cores of infested turf (Nadeau et al., 1993). Even without an added fungicide, Silwet L-77 applied to infested turfgrass significantly increased grass production under greenhouse conditions (Nadeau et al., 1993). Nevertheless, it is possible that a combination of a fungicide and a surfactant might provide greater control than the surfactant alone.

In an attempt to find an effective treatment for fairy ring, a series of experiments were designed to 1) evaluate fungicides for their ability to inhibit $M$. oreades in vitro, 2) test different combinations of fungicides and surfactants under greenhouse conditions, and 3) evaluate the most promising treatments under field conditions.

\section{Materials and Methods}

Screening fungicides in vitro. Twelve fungicide solutions (Table 1) were prepared at twice their recommended concentrations, filter sterilized, and incorporated into agar media ( $2 \%$ agar, $2 \%$ glucose) to produce concentrations that were $100 \%, 20 \%, 4 \%, 0.8 \%$, and $0 \%$ of the recommended rates. Four isolates of $M$. fested, potted turf. Cores of infested turf, 20 $\mathrm{cm}$ in diameter and $10 \mathrm{~cm}$ in depth, were cut from a lawn that had been seeded with an equal mixture of Poa pratensis L. and Festuca rubra L. var. rubra. Because of $M$. oreades infestation, about one-half of the surface of the cores was relatively free of grass; the remainder was covered by grass undergoing the stimulated growth associated with the early stages of this disease (Smith, 1980). The cores were placed in 20 -cm pots half filled with 2 peat : 2 soil : 1 fine sand and maintained in a greenhouse at 22 ${ }^{\circ} \mathrm{C}$ with an 18 -h photoperiod and twice-weekly watering. Five weeks after collection the grass was cut to $10 \mathrm{~cm}$, dried at $65^{\circ} \mathrm{C}$ for $85 \mathrm{~h}$ and weighed. Treatments were applied as a $3 \times 4$ factorial with three surfactant treatments [water control, Silwet L-77 $\left(20 \mathrm{~mL} \cdot \mathrm{L}^{-1}\right)$, Citowett ter control, thiram $\left(7 \mathrm{~g} \cdot \mathrm{L}^{-1}\right)$, copper oxychloride $\left(2 \mathrm{~g} \cdot \mathrm{L}^{-1}\right)$, tribasic copper sulfate $\left.\left(3 \mathrm{~g} \cdot \mathrm{L}^{-1}\right)\right]$, all based on active ingredient. All concentrations represented the recommended application rates. The surfactants and fungicides were mixed and $400 \mathrm{~mL}$ of solution was poured into each pot. The treatment was repeated 1 week later. After 1 more week, $600 \mathrm{~mL}$ of water was added to each pot and after another $4 \mathrm{~d}$, regular watering was resumed. The experiment was a $\left(8 \mathrm{~mL} \cdot \mathrm{L}^{-1}\right)$ ] and four fungicide treatments [wa- 
Table 1. Trade names, \% active ingredients, recommended application rates, manufacturers and registrations [domestic (D) vs. commercial (C)] of fungicides tested in vitro.

\begin{tabular}{llcclc}
\hline \hline Fungicide & \multicolumn{1}{c}{ Trade name } & $\%$ a.i. & $\begin{array}{c}\text { Rate of a.i. } \\
(\mathrm{ppm})\end{array}$ & \multicolumn{1}{c}{ Manufacturer } & Address \\
\hline Phenyl mercuric acetate & PMA-10 (Clean crop) & 10 & 200 & Yellowstone Agri. Products & Richmond, B.C. \\
Copper oxychloride & Copper spray & 50 & 2000 & Later Chemicals & Richmond, B.C. \\
Folpet & Phaltan & 50 & 350 & Later Chemicals & R \\
Chlorothalonil & Lawn fungicide & 30 & 4500 & Chipman & D \\
Maneb & Maneb & 80 & 2500 & Wilson Laboratories & Stoney Creek, Ont. \\
Ferbam & Fruit plus & 15 & 1500 & Chipman & Dundas, Ont. \\
Triforine & Fuginex & 6.5 & 195 & Ciba-Geigy & S \\
Tribasic copper sulphate Creek, Ont. & D \\
Truban & Bordo & 53 & 2385 & Wilson Laboratories & Mississauga, Ont. \\
Oxime benzoate & Tropical plant & 25 & 219 & Dexol & Dundas, Ont. \\
Anilazine & No damp & 2.5 & 250 & Plant Products & Torrance, Calif. \\
Thiram/Oxycarboxin/ & Dyrene & 50 & 5000 & Mobay & Brampton, Ont. \\
Carbathiin & & & & & Kansas City, Mo. \\
& Arrest & $50 / 5 / 20$ & $7000 / 700 / 2800$ & Uniroyal & C \\
\end{tabular}

fully randomized design with 10 pots per treatment combination and the initial grass mass as a covariate. The grass was clipped to a height of $10 \mathrm{~cm}$ six times, between 29 and $130 \mathrm{~d}$ after treatment, dried and weighed. The grass was permitted to grow after this, but no further measurements were made of its mass.

Six months after treatment, three more variables were measured. First, a cube of mineral soil, $3 \mathrm{~cm}$ on a side, was taken from the top $10 \mathrm{~cm}$ of each pot and assessed for bulk density (McKeague, 1976). Second, a cylinder of mineral soil, $4 \mathrm{~cm}$ in diameter and $10 \mathrm{~cm}$ long, was removed and assessed for water absorption capacity following a 5-min immersion in water (Nadeau et al., 1993). Third, pots were examined for the distinctive mycelium of $M$. oreades; this was done "blindly" such that the person evaluating the turf was unaware of the treatment that had been applied. Although 120 pots had been treated, one pot was lost and several were sacrificed in refining techniques. Thus, only 109, 106, and 111 experimental units were evaluated for bulk density, water uptake and mycelium, respectively.

SAS PROC GLM (SAS, 1989) was used to analyze data for grass production, bulk density, and water absorption capacity. The model for grass production was the following:

$\mathrm{Y}_{\mathrm{ijk}}=\mu+\mathrm{F}_{\mathrm{i}}++\mathrm{S}_{\mathrm{j}}+(\mathrm{FS})_{\mathrm{ij}}+\mathrm{B}\left(\mathrm{X}_{\mathrm{ijk}}\right)+\mathrm{e}_{\mathrm{ijk}}$ where

$\mathrm{Y}=$ Dependent variable.

$\mu=$ Overall mean.

$\mathrm{F}=$ Fungicide treatment.

$\mathrm{S}=$ Surfactant treatment.

$\mathrm{FS}=$ Fungicide $\times$ surfactant interaction .

$\mathrm{X}=$ Initial turf mass.

$\mathrm{B}=$ Regression coefficient for the relation between $\mathrm{Y}$ and $\mathrm{X}$.

$\mathrm{e}=$ Experimental error.

A similar model, without initial mass as covariate was used to evaluate treatment effects on water uptake and bulk density. Fisher's exact test (Stokes et al., 1995) was used to evaluate treatment effects on mycelium frequency.

Occurrence of mycelium in potted turf treated with two organosilicone surfactants. Seventy-five cores of infested turf were collected and maintained in the greenhouse as described above. One month later the turf was drenched with either $400 \mathrm{~mL}$ of water, Silwet $\mathrm{L}-77$ at $9 \mathrm{~mL} \cdot \mathrm{L}^{-1}$, or Sylgard at $9 \mathrm{~mL} \cdot \mathrm{L}^{-1}$. Three days later, $600 \mathrm{~mL}$ of water was applied to all pots. The procedure was repeated 1 week later. The turf in five pots per treatment was destructively sampled and the presence of mycelium was blindly evaluated $14,37,56,78$, and $99 \mathrm{~d}$ after treatment. The experiment was a fully randomized design with five pots per treatment per evaluation time.

Field evaluation of chlorothalonil and two organosilicone surfactants. The experiment was conducted in an isolated area, $\approx 200 \times 100$ $\mathrm{m}$, located within a city park in Edmonton, Alberta. The area had been planted with an equal mixture of Poa pratensis L. and Festuca rubra L. var. rubra and was regularly mowed, but neither fertilized nor watered. Several hundred rings were present. The treatment structure was a $3 \times 2$ factorial with three levels of surfactant [water, Silwet L-77 $\left(13.1 \mathrm{~mL} \cdot \mathrm{L}^{-1}\right)$ and Sylgard $\left.\left(13.1 \mathrm{~mL} \cdot \mathrm{L}^{-1}\right)\right]$ and two levels of fungicide [water and chlorothalonil (1.06 $\left.\left.\mathrm{g} \cdot \mathrm{L}^{-1}\right)\right]$. Surfactant and fungicide solutions were mixed prior to application. The design structure in 1992 was a split plot. There were 12 blocks, each with two main plots consisting of two fairy rings of about equal disease severity. The two fungicide treatments were randomly assigned to rings within a block. Surfactant treatments were randomly assigned to subplots consisting of rectangular areas $85 \times 50$ $\mathrm{cm}$ superimposed on the rings with the long axis perpendicular to the ring and the short edge located $35 \mathrm{~cm}$ from the margin between the zones of stimulated grass growth and grass mortality (Fig. 1). In addition, three control blocks were established in healthy turf. Each control block consisted of two rows of three 85 $\times 50$-cm plots; fungicide treatments were randomly assigned to the rows and surfactant treatments were randomly assigned to the plots within rows. The control blocks were not randomly placed in the experimental area; two of them were close to each other in a location that appeared to be wetter than average. Treatments were applied on 2 June and 29 July as a 4-L drench followed by a 6-L water drench. Rainfall was monitored and supplemented by watering, when necessary, to ensure that the plots received at least $2.35 \mathrm{~cm}$ of water per week.

Except as noted, all sampling was done in a $25 \times 25-\mathrm{cm}$ area positioned such that $5 \mathrm{~cm}$ of the sampling area was located beyond the margin between the zones of stimulated grass growth and grass mortality (Fig. 1). Grass productivity was determined by placing a 3.8$\mathrm{cm}$-high metal frame over the sampling area and cutting the grass to that height on four dates between 22 July and 23 Sept. Grass

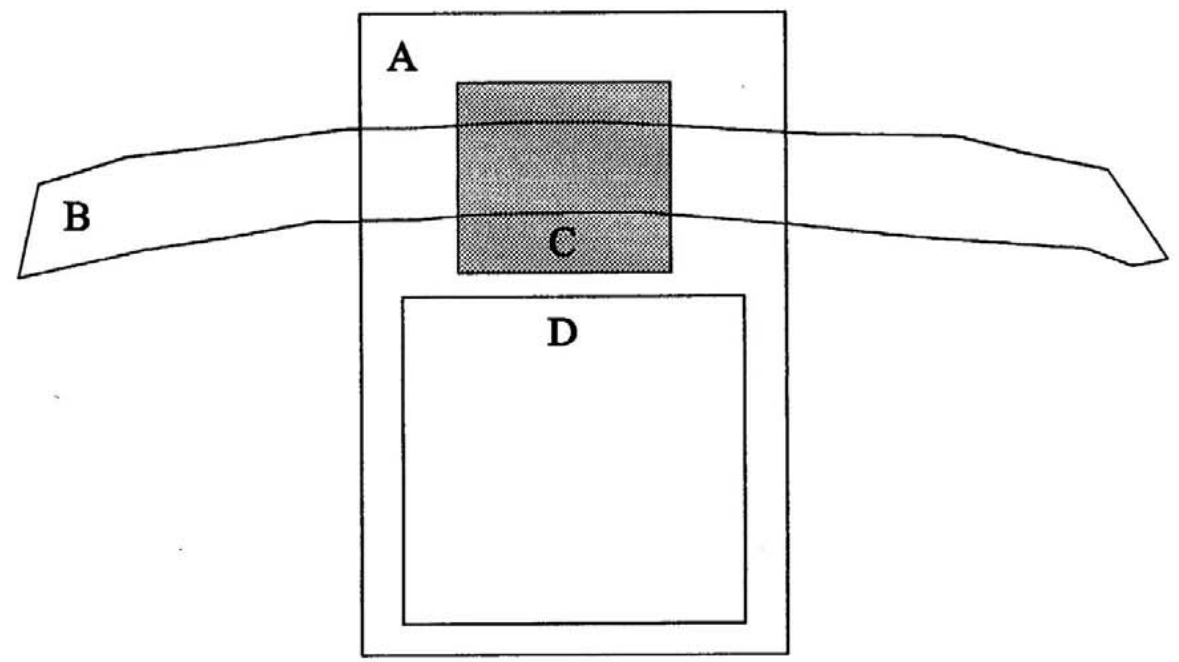

Fig. 1. Location and orientation of treatment and sampling zones in the field experiment. Treatments were applied in an $85 \times 50$-cm treatment zone (A) perpendicular to the fairy ring (B). Mushrooms were sampled in zone A; grass production, acute foliar phytotoxicity, canopy cover, soil water content and the occurrence of mycelium were determined in zone C; and chronic phytotoxicity was determined in zone D.

HortScience, Vol. 32(6), OCtOBER 1997 
cover was evaluated on 8 Sept. by placing a wire grid with twenty-five $5 \times 5$-cm quadrats over the sampling area and having two independent observers estimate the percentage of quadrats with more than $50 \%$ of the surface area covered by grass. Mushrooms were collected over the entire $85 \times 50$-cm treatment area on nine occasions between 6 July and 13 Sept., dried and weighed.

In 1993, six new infected blocks and three new control blocks were treated at the same time and manner as in the previous year. Six infected blocks and two control blocks from 1992 were retreated. Sampling was done as before with the following exceptions. First, because the rings had expanded in some cases, the sampling zone for the water control on each ring was moved forward so that it extended $5 \mathrm{~cm}$ beyond the margin between killed and stimulated grass; sampling zones for the surfactant treatments were moved forward by the same distance. Second, the precision of canopy cover measurements might have been improved by measuring cover on a continuous, rather than a binary, scale. Hence, when canopy cover was measured on 28 Sept., a square grid divided into four $10 \times 10-\mathrm{cm}$ quadrats was placed over the sampling area and the percentage of grass cover in each quadrat was assessed independently by two observers. Finally, mushrooms were counted, but not weighed, on nine different dates between 6 July and 13 Sept.

Since uniform color is a desired feature of turfgrass, fairy ring treatments should be evaluated for their ability to eliminate the darkening associated with infested turf. Because this darkening was not easily quantified on individual grass blades, chlorophyll content was measured (Vernon, 1960) on 8 Sept. 1993 as a surrogate for color. Twenty blades of grass were randomly selected from each sampling area, cut to a height of $4 \mathrm{~cm}$, and placed in paper envelopes that were then put in a plastic bag in a cooler containing ice. Five of the twenty grass blades were weighed, cut into small pieces, and blended in $10 \mathrm{~mL}$ of $80 \%$ acetone. An additional $10 \mathrm{~mL}$ of acetone was added to the mixture, and then $1.5 \mathrm{~mL}$ was removed and centrifuged for $5 \mathrm{~min}$. Chlorophyll A and B levels were determined by measuring the absorbance at 649 and $665 \mathrm{~nm}$, respectively. The remaining 15 blades were used to determine the wet mass : dry mass ratio for the grass. The values of total chlorophyll on a dry mass basis were analyzed.

Acute phytotoxicity was measured in 1992 by first having two independent observers estimate the percentage of twenty-five $5 \times 5$ $\mathrm{cm}$ quadrats with more than $50 \%$ of the surface area covered by grass on the day prior to the second surfactant application. Nine days later the percentage of quadrats with more than $50 \%$ of the surface area covered by injury-free grass was determined; the difference between these two measures of cover was used as an index of phytotoxicity. Chronic phytotoxicity was determined in Aug. 1994 in $40 \times 40-\mathrm{cm}$ portions of treated areas where the grass appeared unaffected by the pathogen. (Fig. 1). The grass in that area was cut to a height of 10 $\mathrm{cm}$ and two independent observers ranked the Silwet L-77, Sylgard and water treatments on the basis of apparent shoot density. Friedman's test (Conover, 1980) was used to determine if there were differences among surfactant treatments.

On 23 June 1994, three soil cores, $2 \mathrm{~cm}$ in diameter and $6 \mathrm{~cm}$ long, were collected from each sampling area (Fig. 1). One was blindly evaluated for the presence of $M$. oreades mycelium and the other two were weighed, dried, and reweighed to determine water content.

SAS PROC MIXED (Littell et al., 1996) was used to analyze data for grass production, canopy cover, water content, and chlorophyll content. The model was the following:

$\mathrm{Y}_{\mathrm{ijkl}}=\mu+\mathrm{T}_{\mathrm{i}}+\mathrm{B}_{\mathrm{j}}\left(\mathrm{T}_{\mathrm{i}}\right)+\mathrm{F}_{\mathrm{k}}+(\mathrm{FT})_{\mathrm{ik}}+\mathrm{e}_{\mathrm{ijk}}+\mathrm{S}_{1}$ $+(\mathrm{TS})_{\mathrm{il}}+(\mathrm{FS})_{\mathrm{kl}}+(\mathrm{TFS})_{\mathrm{ik}}+\mathrm{E}_{\mathrm{ijkl}}$

where

$\mathrm{Y}=$ Dependent variable.

$\mu=$ Overall mean.

$\mathrm{T}=$ Time of treatment, 1992 only, 1993 only, or both 1992 and 1993.

$\mathrm{B}=\mathrm{Block}$, nested within time of treatment.

$\mathrm{F}=$ Fungicide treatment, either chlorothalonil or water control.

FT $=$ Time $\times$ fungicide interaction.

$\mathrm{e}=$ Error term for testing fungicide effect.

$\mathrm{S}=$ Surfactant treatment, either Silwet L77 , Sylgard, or water control.
TS, FS, TFS = Interaction of surfactant with time, fungicide, and time $\times$ fungicide, respectively.

$E=$ Error term for testing surfactant and surfactant $\times$ fungicide effects.

Because of the nonrandom placement of uninfested plots in 1992 and because of a tendency for variances to be heterogeneous between diseased and healthy plots, the data were analyzed separately for diseased and healthy plots. Because the effects of surfactants often varied with the year of treatment and examination and because the interpretation of treatment year would not be straightforward, treatment effects were calculated separately by year of treatment and examination. However, because error variances typically were homogeneous among years, the data from all years were used to estimate common error variances for the different years.

\section{Results}

Screening fungicides in vitro. Five of the fungicides, thiram, tribasic copper sulfate, copper oxychloride, anilazine, and phenyl mercuric acid seemed most effective in inhibiting fungal growth in the first experiment (Fig. $2 \mathrm{~A})$. In the second experiment, thiram completely inhibited fungal growth and there were
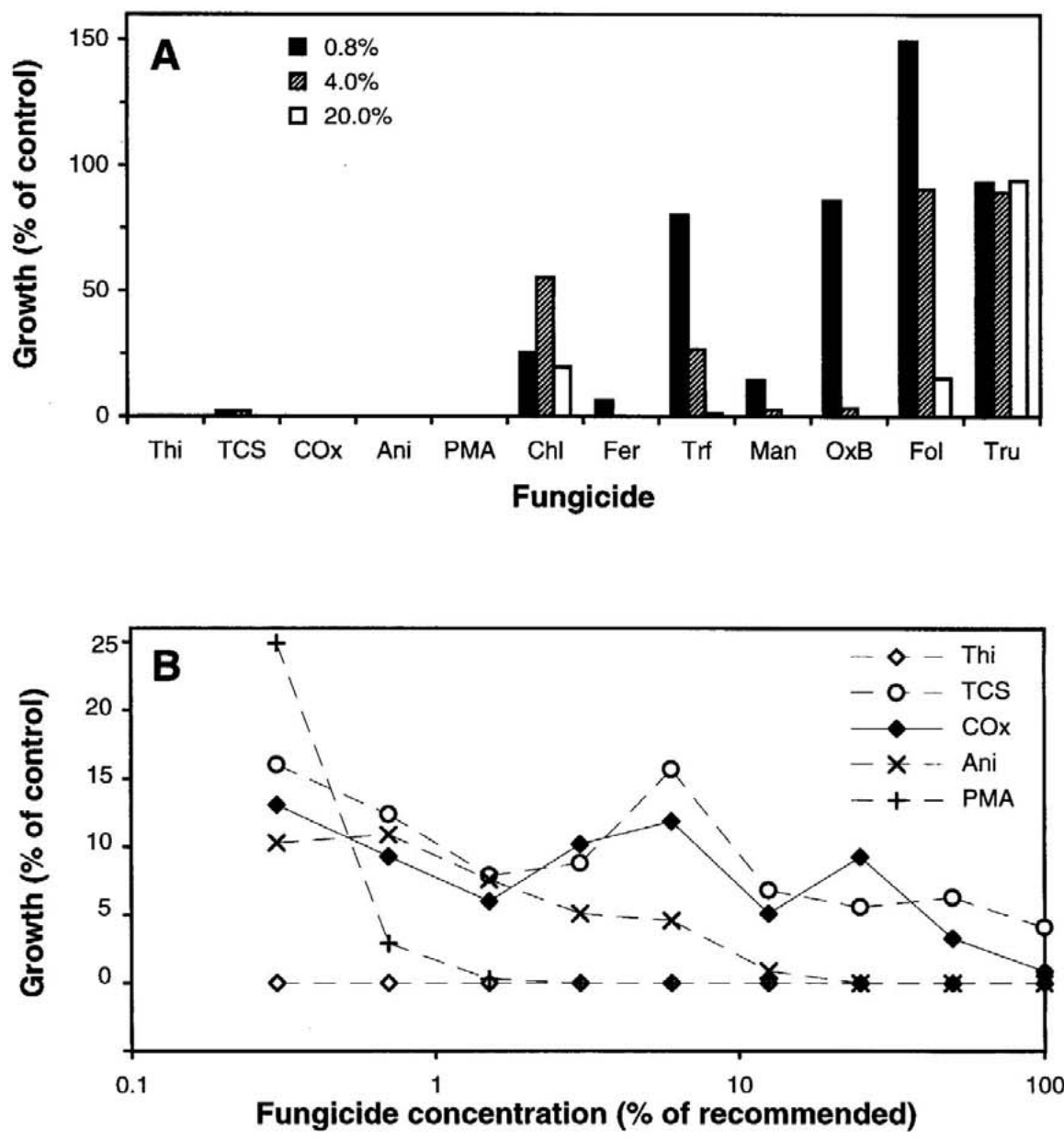

Fig. 2. Average growth in diameter of four $M$. oreades isolates on agar medium amended with 12 fungicides (see Table 1) applied at $0.8 \%, 4.0 \%$, and $20.0 \%$ of their recommended rates (A) or amended with five different fungicides at 10 concentrations, including a water control (B). Growth is expressed as a percentage of growth in the absence of fungicide. 
no significant $(P<0.05)$ differences among the other fungicides at any of the concentrations (Table 2, Fig. 2B).

Fungicide and surfactant effects on infested, potted turf. Thiram significantly reduced grass production (Fig. 3A), thus this treatment was not considered in subsequent analysis of turf growth. The surfactant treatments significantly increased biomass production (Table 3), with Silwet L-77 being more effective than Citowett. On average, the two surfactants increased grass growth by $71 \%$ relative to the water control and Silwet L77 resulted in $14 \%$ more grass yield than Citowett. Other than the negative effect of thiram, there was neither a fungicide effect nor a surfactant $\times$ fungicide interaction. The effects of surfactants and fungicides on water absorption by soil cores paralleled those on grass growth. The two surfactants increased water uptake by an average of $48 \%$, Silwet L77 was $32 \%$ more effective than Citowett, and there was neither a fungicide, nor a fungicide by surfactant interaction (Table 3, Fig. 3B). None of the treatments affected soil bulk density. At the end of the experiment, mycelium typical of $M$. oreades was present in 11 of 38 pots treated with no surfactant, 7 of 37 pots treated with Citowett, and none of the 36 pots treated with Silwet L-77. Relative to the water control, the frequency of pots with mycelium was significantly lower for the Silwet L-77 treatment, but not for the Citowett treatment $(P<0.0001$ and $P=0.248$, respectively).

Occurrence of mycelium in potted turf treated with two organosilicone surfactants. Mycelium typical of $M$. oreades was found in all pots, at all times after treatment with water (Fig. 4). In contrast, the frequency of mycelium in pots treated with either Sylgard or Silwet L-77 decreased with time, such that no mycelium was visible at or after $78 \mathrm{~d}$.

Field evaluation of chlorothalonil and two organosilicone surfactants. The original plan had been to screen domestic fungicides for their toxicity to the pathogen and combine them with surfactants for fairy ring control. Two of the five best-performing fungicides in the in vitro test (copper oxychloride and tribasic copper sulfate) had no effect in the greenhouse, and a third (thiram) reduced grass production. Of the remaining two, anilazine was not registered for domestic use and phenyl mercuric acetate was considered undesirable because it contained mercury. Hence chlorothalonil was used in the field experiment.

Typically, there were no fungicide effects, surfactant by fungicide interactions or differences between Silwet L-77 and Sylgard, regardless of the year in which plots were treated or examined, regardless of which variables were measured, and regardless of whether the plots were infested or healthy (Tables 4 and 5). Because there were typically no differences between Silwet L-77 and Sylgard, analysis focused on the difference between surfactant treatments (averaged over Silwet L-77 and Sylgard) and the water control. Typically, these differences were significant and often very large.

Table 2. Analysis of variance for the effects of four different fungicides on mean fungal growth and the linear trend of fungal growth with increasing fungicide concentration.

\begin{tabular}{|c|c|c|c|c|c|}
\hline \multirow[b]{2}{*}{ Source } & \multirow[b]{2}{*}{ df } & \multicolumn{2}{|c|}{ Mean } & \multicolumn{2}{|c|}{ Linear trend } \\
\hline & & Sum sq. & $P$ & Sum sq. & $P$ \\
\hline Fungicide & 3 & 1367 & 0.180 & 28 & 0.957 \\
\hline Error & 12 & 2843 & & 1117 & \\
\hline Total & 15 & 4210 & & 1145 & \\
\hline
\end{tabular}
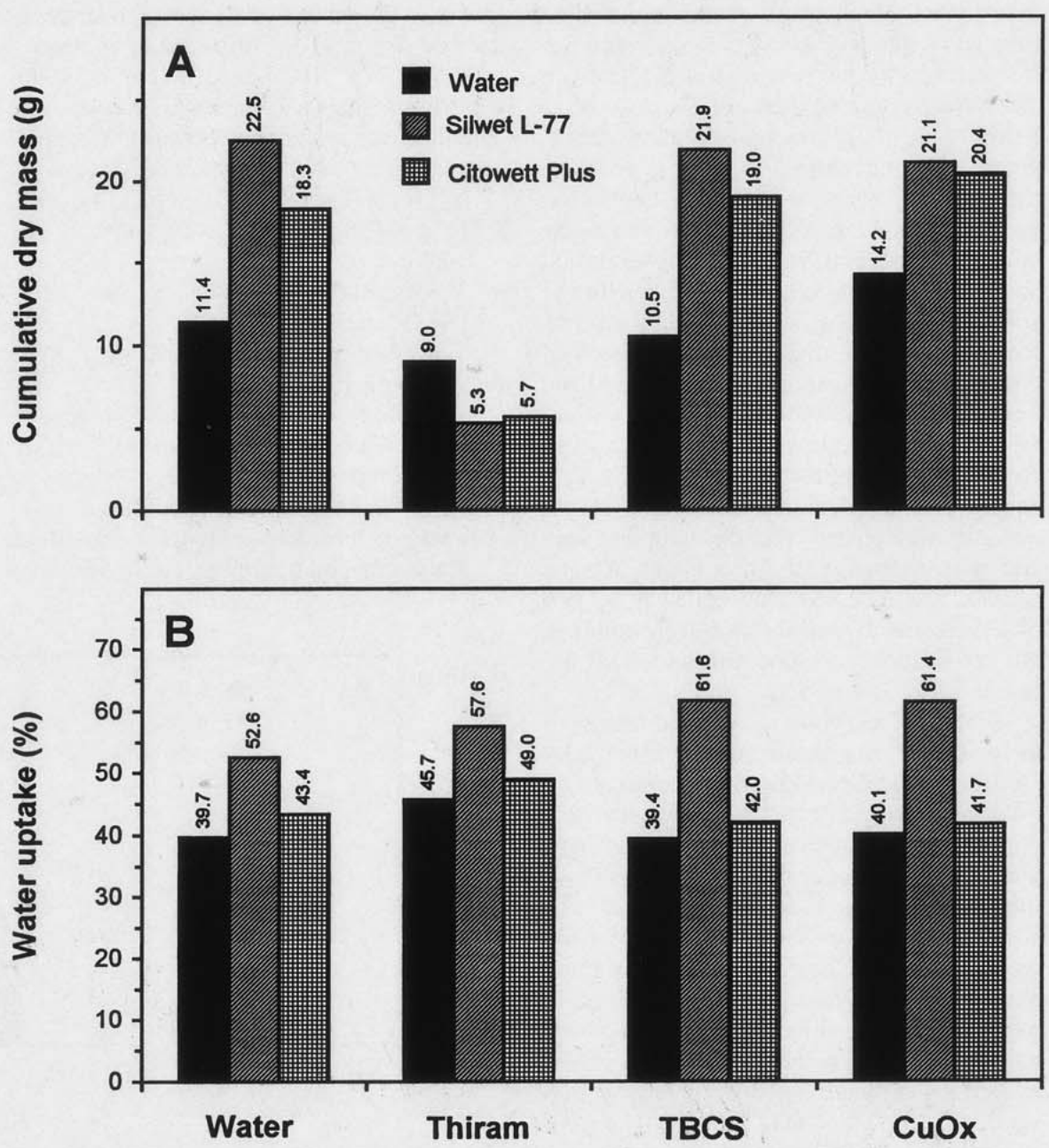

Fig. 3. (A) Cumulative grass production over 130 days by turf treated with surfactants (water, Citowett Plus, or Silwet L-77) in combination with fungicides (water, thiram, tribasic copper sulfate, or copper oxychloride). Thiram resulted in less grass production than water $(P<0.001)$. Following exclusion of the latter treatment, there were neither fungicide $(P=0.289)$ nor fungicide by surfactant $(P=0.323)$ interaction effects, whereas surfactants, on average, increased grass production $(P<0.001)$ and Silwet L-77 was more effective than Citowett Plus $(P=0.009)$. (B) Water uptake, as a percentage of oven dry mass, by soil cores from treated turf. There was neither fungicide $(P=0.098)$ nor fungicide by surfactant $(P=0.154)$ interaction effects, whereas surfactants, on average, increased grass production $(P<0.001)$ and Silwet L-77 was more effective than Citowett Plus $(P<0.001)$.

Organosilicone treatment greatly increased grass production in diseased turf in the year of initial application (Fig. 5A). In infested plots that were treated and sampled in 1992 or 1993 , surfactant treatment caused an increase in grass productivity of about $200 \%$. On diseased plots treated in 1992 but not retreated the following year there was still a significant increase in grass production in 1993; the difference in biomass between surfactant-treated and water-treated plots was more than $40 \%$. Among diseased plots treated in both 1992 and 1993 there was no difference between plots treated with surfactant and those treated with water.
The pattern of surfactant effects on biomass yields in uninfested plots was different from the pattern in infested plots (Table 4). Relative to the water control, the surfactant treatment increased grass production both on plots treated and sampled in 1992 and on those treated and sampled only in 1993. Surfactants decreased grass production both on plots that were treated only in 1992 and sampled in 1993 and on those that were treated in both 1992 and 1993 and sampled in 1993. In the latter case, biomass production was reduced by nearly $50 \%$ (Fig. 5A).

The effect of surfactants on the canopy 
cover of infested plots varied with the year in which the surfactants were applied (Table 4, Fig. 5B). Infested plots treated with surfactant in only 1992 had greater cover than watertreated plots regardless of whether the plots were examined in 1992 or 1993 . In contrast, infested plots treated with surfactant in both years or only in 1993, had less cover than the water treated plots, although the differences were not large.

Surfactants reduced the canopy cover of uninfested plots regardless of year of treatment or year of examination, although the differences were significant only for plots treated in 1992 or in both 1992 and 1993 and examined in 1993. In both these cases, however, cover was reduced by about half.

Regardless of year of treatment, the surfactants had an enormous effect on mushroom production (Fig. 6). In 1992, mushrooms were produced in all 24 plots treated with water and in only four of 48 surfactant-treated plots. In 1993, mushrooms were present on all 36 water-treated plots but on only 10 of 72 plots that had been treated with surfactant. There was no significant difference between Silwet L-77 and Sylgard in the frequency of plots with mushrooms.

On plots that had not been treated with surfactant, chlorothalonil reduced mushroom production relative to the no-fungicide control by $41 \%(P=0.027)$ in 1992 . In 1993 , mushroom production on plots that had been treated with fungicide alone was reduced by $40 \%(P=$ $0.063), 34 \%(P=0.039)$, and $50 \%(P=0.040)$ on plots treated in 1992 only, 1993 only, and in both 1992 and 1993, respectively. On plots treated with organosilicones, there was no significant fungicide effect on mushroom production in either year.

Surfactant treatment greatly reduced the occurrence of mycelium in cores taken in 1994,1 or 2 years after the last treatment. Mycelium was present in 33 of 36 plots treated with water only. In contrast, mycelium was found in only six of 72 cores from surfactanttreated plots. Although this surfactant effect was highly significant, regardless of whether the plots had been treated in 1992 only, 1993 only, or both 1992 and 1993, five of the six infested cores came from plots treated in 1992 only.

Treatment with surfactant in 1992 only, or in both 1992 and 1993, significantly reduced chlorophyll content, regardless of whether or not the plots were infested (Table 5A, Fig. 7A). In contrast, there was no surfactant effect on plots treated in 1993 only, regardless of whether or not they were infested. Although not formally analyzed, grass from diseased plots contained more chlorophyll than did that from healthy plots regardless of year or surfactant treatment.

The surfactant treatment significantly increased water content of soil in infested plots regardless of the year of application (Table 5B, Fig. 7B). Relative to the water control, surfactant treatment increased soil water content by $40 \%, 63 \%$, and $56 \%$ in plots treated in only 1992, only 1993, and in both 1992 and 1993, respectively. On uninfested plots treated

Table 3. Analysis of variance for the effects of surfactants and fungicides on cumulative grass production (dry mass), uptake of water by soil, and soil bulk density.

\begin{tabular}{|c|c|c|c|c|c|c|c|c|c|}
\hline \multirow[b]{3}{*}{ Source } & \multicolumn{3}{|c|}{ Grass production } & \multicolumn{3}{|c|}{ Water uptake } & \multicolumn{3}{|c|}{ Bulk density } \\
\hline & & Sum & & & Sum & & & Sum & \\
\hline & df & sq. & $P$ & df & sq. & $P$ & df & sq. & $P$ \\
\hline$\overline{\text { Covariate }^{z}}$ & 1 & 41 & 0.090 & $\ldots$ & -.. & -.. & --- & -- & --- \\
\hline Surfactant (S) & 2 & 1521 & 0.001 & 2 & 5864 & 0.001 & 2 & 1.33 & 0.304 \\
\hline $\begin{array}{l}\text { Water vs. } \\
\text { organosilicone } \\
\text { Between }\end{array}$ & 1 & 1424 & 0.001 & 1 & 2341 & 0.001 & 1 & -- & -- \\
\hline organosilicones ${ }^{y}$ & 1 & 93 & 0.009 & 1 & 3533 & 0.001 & 1 & $\cdots$ & -- \\
\hline Fungicide $(\mathrm{F})$ & 2 & 35 & 0.289 & 3 & 406 & 0.098 & 3 & 1.48 & 0.444 \\
\hline $\mathrm{S} \times \mathrm{F}$ & 4 & 65 & 0.323 & 6 & 604 & 0.154 & 6 & 3.39 & 0.412 \\
\hline Error & 79 & 1080 & & 94 & 5887 & & 97 & 53.35 & \\
\hline Total & $88^{x}$ & 2730 & & $105^{x}$ & 12803 & & $108^{x}$ & 59.53 & \\
\hline
\end{tabular}

Initial grass mass was used as a covariate in analyzing grass productivity.

'If the surfactant effects were significant, they were partitioned into single degree of freedom contrasts between 1) the water control and the organosilicone treatment and 2) the two organosilicones.

*Although 120 pots were treated, one was lost, the thiram treatment was excluded in the analysis of grass productivity, and 13 and 10 pots were sacrificed for developing methods for evaluating water uptake and bulk density, respectively.

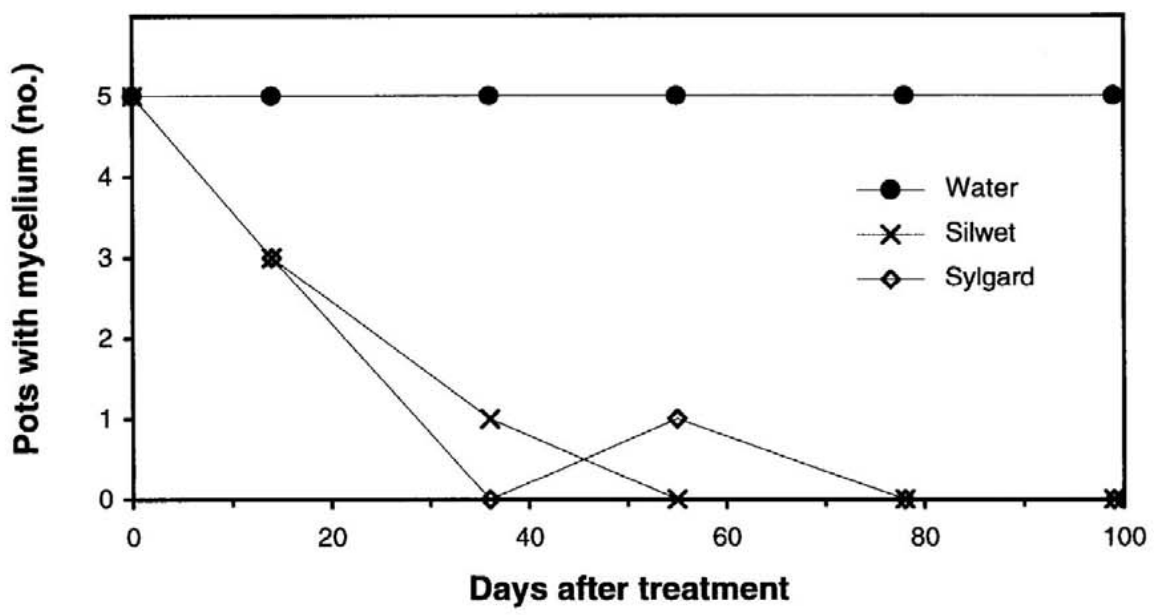

Fig. 4. Number of pots (out of five per treatment) possessing mycelium typical of $M$. oreades at various times after treatment with water, Silwet L-77, or Sylgard.

only in 1992, water treatment resulted in higher moisture content than did surfactant treatment; the reverse was true for uninfested plots treated in both 1992 and 1993, and there was no difference between the two treatments in uninfested plots treated in 1993 only. The Silwet L-77 treatment was associated with more soil moisture than the Sylgard treatment on uninfested plots treated in both 1992 and 1993, but otherwise there were no differences between these compounds.

Acute surfactant-induced phytotoxicity was not detected in infested plots in 1992. There was however, strong evidence for phytotoxicity in the uninfested plots. Prior to the second surfactant application there were $160 \%$ more quadrats with $>50 \%$ healthy grass in the surfactant-treated plots than in water-treated plots. After the second treatment, there were nearly 3 times as many quadrats with $>50 \%$ healthy grass in the watertreated plots than in the surfactant-treated plots. There was no evidence of chronic phytotoxicity; shoot density in uninfested turf did not differ among treatments regardless of whether the data were analyzed separately by year of treatment or combined across all years.

\section{Discussion}

On infested plots treated in either 1992 or 1993 and sampled later that same year, organosilicone surfactants greatly increased grass productivity. In both years surfactanttreated plots produced more than 3 times as much biomass as did water-treated plots (Fig. 5A). Among those plots that were treated and sampled the same year, there also seemed to be more grass in infested plots than in healthy turfgrass following treatment with surfactants. There might have been more $\mathrm{N}$ in infested than uninfested soil (Shantz, 1917). Addition of the organosilicone solutions might have rendered this $\mathrm{N}$ available, thus causing a larger increase in grass production in the infested than in the uninfested turf. The increase in canopy cover in response to surfactant treatment was not as great as the increase in biomass production (Fig. 5B). This was particularly striking in diseased plots that were treated and examined in 1993. Relative to the water control, surfactants increased biomass by $200 \%$, whereas canopy cover was decreased by $14 \%$. Some of the apparent inconsistency between biomass production and canopy cover might have arisen because increasing water and nutrients in- 
Table 4. Observed levels of significance ( $P$ values) following analysis of variance for the effects of surfactants and fungicides on cumulative dry weight of grass production and canopy cover. Treatments were applied to either diseased (Dis) or healthy (Hea) turf in either 1992, 1993, or in both years. Plots were examined in 1992 or 1993.

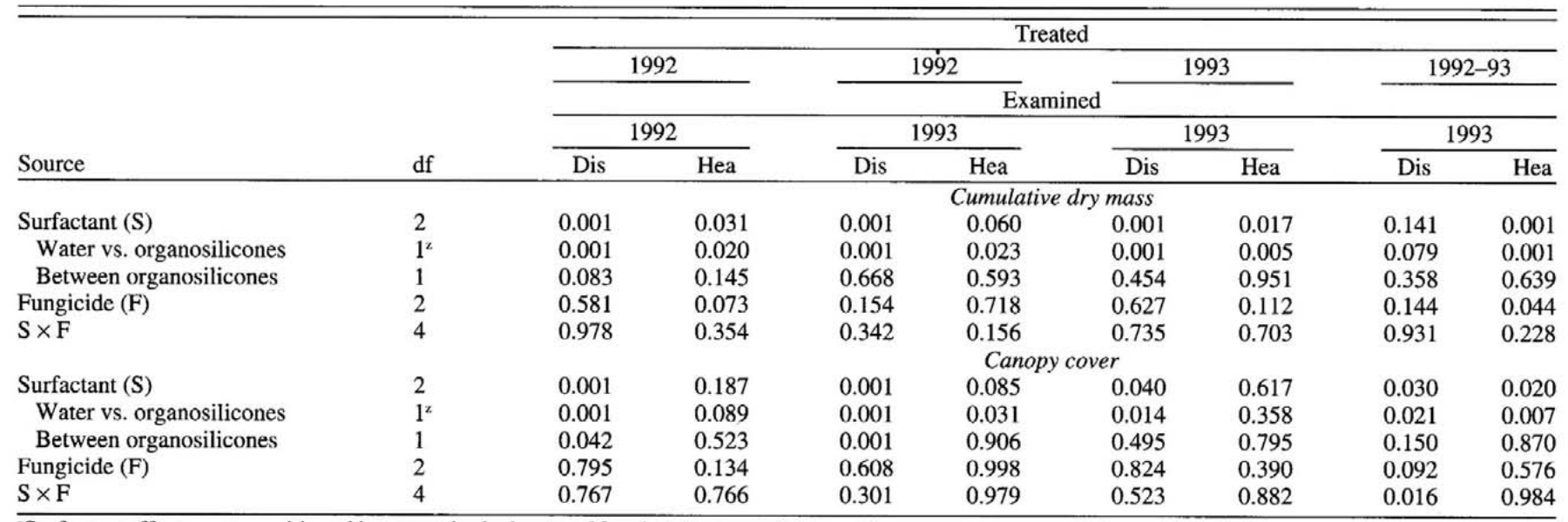

${ }^{\mathrm{r}}$ Surfactant effects were partitioned into two single degree of freedom contrasts: between the water treatment and the average of the two organosilicone treatments and between the two organosilicone treatments.

creased leaf elongation rather than leaf number. The difficulty in precisely measuring canopy cover may also have contributed to this discrepancy.

On infested plots that were treated only in 1992 and sampled in 1993, the organosilicones significantly increased both canopy cover and grass production, relative to the water control (Fig. 5). These increases seemed less than those observed when 1992-treated plots were examined in 1992, although no formal comparison was done. In the case of canopy cover, part of this difference may have resulted from different sampling methods that were used in the two years. In the case of grass production, the 1992 treatment might have increased available nitrogen, leading to an initial growth flush and some degree of soil nutrient exhaustion, followed by a smaller growth increase in 1993 .

On infested plots treated in both 1992 and 1993 and examined in 1993, the organosilicone treatment caused a significant decrease in canopy cover and a numerical decrease in production that approached statistical significance, relative to the water control (Fig. 5). Once again, exhaustion of soil nutrients could be a possible explanation. This explanation is somewhat unlikely, however, since those plots that were treated in 1992 only and examined in 1993 were still showing an increase in production in 1993, albeit less than in the previous year. An alternative explanation is that treating plots two years in succession led to phytotoxicity.

There is indirect evidence that the surfactants caused chronic phytotoxicity in the uninfested plots, although in interpreting these results it must be emphasized that there were far fewer healthy than diseased plots. For example, only one uninfested block was treated only in 1992 and evaluated in 1993. Also, in 1992 the plots were not randomly positioned. Nevertheless, on those uninfested plots that were either treated in 1992 only and examined in 1993 or treated in both 1992 and 1993 and examined in 1993, both canopy cover and grass production were significantly reduced in response to the organosilicones (Fig. 5). Since

Table 5A. Observed levels of significance ( $P$ values) following analysis of variance for the effects of surfactants and fungicides on chlorophyll content. Treatments were applied to either diseased (Dis) or healthy (Hea) turf in either 1992, 1993, or in both years. Plots were examined in 1993.

\begin{tabular}{|c|c|c|c|c|c|c|c|}
\hline \multirow[b]{5}{*}{ Source } & \multirow[b]{5}{*}{$\mathrm{df}$} & \multicolumn{6}{|c|}{ Treated } \\
\hline & & \multicolumn{2}{|c|}{1992} & \multicolumn{2}{|c|}{1993} & \multicolumn{2}{|c|}{$1992-93$} \\
\hline & & & & \multicolumn{2}{|c|}{ Examined } & & \\
\hline & & \multicolumn{2}{|c|}{1993} & \multicolumn{2}{|c|}{1993} & \multicolumn{2}{|c|}{1993} \\
\hline & & Dis & Hea & Dis & Hea & Dis & Hea \\
\hline & & \multicolumn{6}{|c|}{ Chlorophyll } \\
\hline Surfactant (S) & 2 & 0.003 & 0.108 & 0.892 & 0.851 & 0.086 & 0.019 \\
\hline Water vs. organosilicones ${ }^{2}$ & 1 & 0.001 & 0.050 & 0.637 & 0.590 & 0.041 & 0.009 \\
\hline Between organosilicones & 1 & 0.990 & 0.438 & 0.949 & 0.910 & 0.347 & 0.088 \\
\hline Fungicide $(\mathrm{F})$ & 2 & 0.759 & 0.231 & 0.258 & 0.304 & 0.641 & 0.276 \\
\hline $\mathrm{S} \times \mathrm{F}$ & 4 & 0.487 & 0.629 & 0.896 & 0.418 & 0.773 & 0.852 \\
\hline
\end{tabular}

${ }^{2}$ Surfactant effects were partitioned into two single degree of freedom contrasts: between the water treatment and the average of the two organosilicone treatments and between the two organosilicone treatments.

Table 5B. Observed levels of significance ( $P$ values) following analysis of variance for the effects of surfactants and fungicides on soil moisture. Treatments were applied to either diseased (Dis) or healthy (Hea) turf in either 1992, 1993, or in both years. Plots were examined in 1994.

\begin{tabular}{|c|c|c|c|c|c|c|c|}
\hline \multirow[b]{5}{*}{$\underline{\text { Source }}$} & \multirow[b]{5}{*}{$\mathrm{df}$} & \multicolumn{6}{|c|}{ Treated } \\
\hline & & \multicolumn{2}{|c|}{1992} & \multicolumn{2}{|c|}{1993} & \multicolumn{2}{|c|}{$1992-93$} \\
\hline & & & & \multicolumn{2}{|c|}{ Examined } & & \\
\hline & & \multicolumn{2}{|c|}{1994} & \multicolumn{2}{|c|}{1994} & \multicolumn{2}{|c|}{1994} \\
\hline & & Dis & Hea & Dis & $\mathrm{Hea}$ & Dis & Hea \\
\hline & & \multicolumn{6}{|c|}{ Moisture } \\
\hline Surfactant (S) & 2 & 0.001 & 0.071 & 0.001 & 0.124 & 0.001 & 0.010 \\
\hline Water vs. organosilicones & 1 & 0.001 & 0.027 & 0.001 & 0.218 & 0.001 & 0.014 \\
\hline Between organosilicones & 1 & 0.783 & 0.813 & 0.167 & 0.088 & 0.702 & 0.019 \\
\hline Fungicide $(\mathrm{F})$ & 2 & 0.226 & 0.357 & 0.622 & 0.935 & 0.952 & 0.314 \\
\hline $\mathrm{S} \times \mathrm{F}$ & 4 & 0.974 & 0.26 & 0.605 & 0.443 & 0.452 & 0.219 \\
\hline
\end{tabular}

${ }^{2}$ Surfactant effects were partitioned into two single degree of freedom contrasts: between the water treatment and the average of the two organosilicone treatments and between the two organosilicone treatments.

healthy plots treated and examined in 1992 showed no increase in canopy cover, and only a small increase in grass production, this reduction in 1993 was probably not due to exhaustion of nutrients following a growth burst in 1992. On the other hand, although there was evidence of acute phytotoxicity, as evidenced by foliar symptoms soon after surfactant application, there was no direct evidence of chronic phytotoxicity.

Treatment with surfactants greatly reduced the amount $M$. oreades (Fig. 6). This phenomenon was consistently observed in two separate greenhouse experiments and in the field, regardless of the year of treatment or examination and regardless of whether mycelium or mushrooms were measured. Growth of $M$. oreades incubated in a $0.031 \%$ solution of Silwet L-77 was reduced only by $\approx 65 \%$ (Nadeauet al., 1993), suggesting that the pathogen is relatively tolerant of the surfactant. This in turn implies that the effect of the organosilicones was probably indirect, perhaps mediated by changes in the physical or biological characteristics of the soil.

Because of the difficulties in evaluating grass color, chlorophyll content was measured $41 \mathrm{~d}$ after the last treatment in 1993 to deter- 

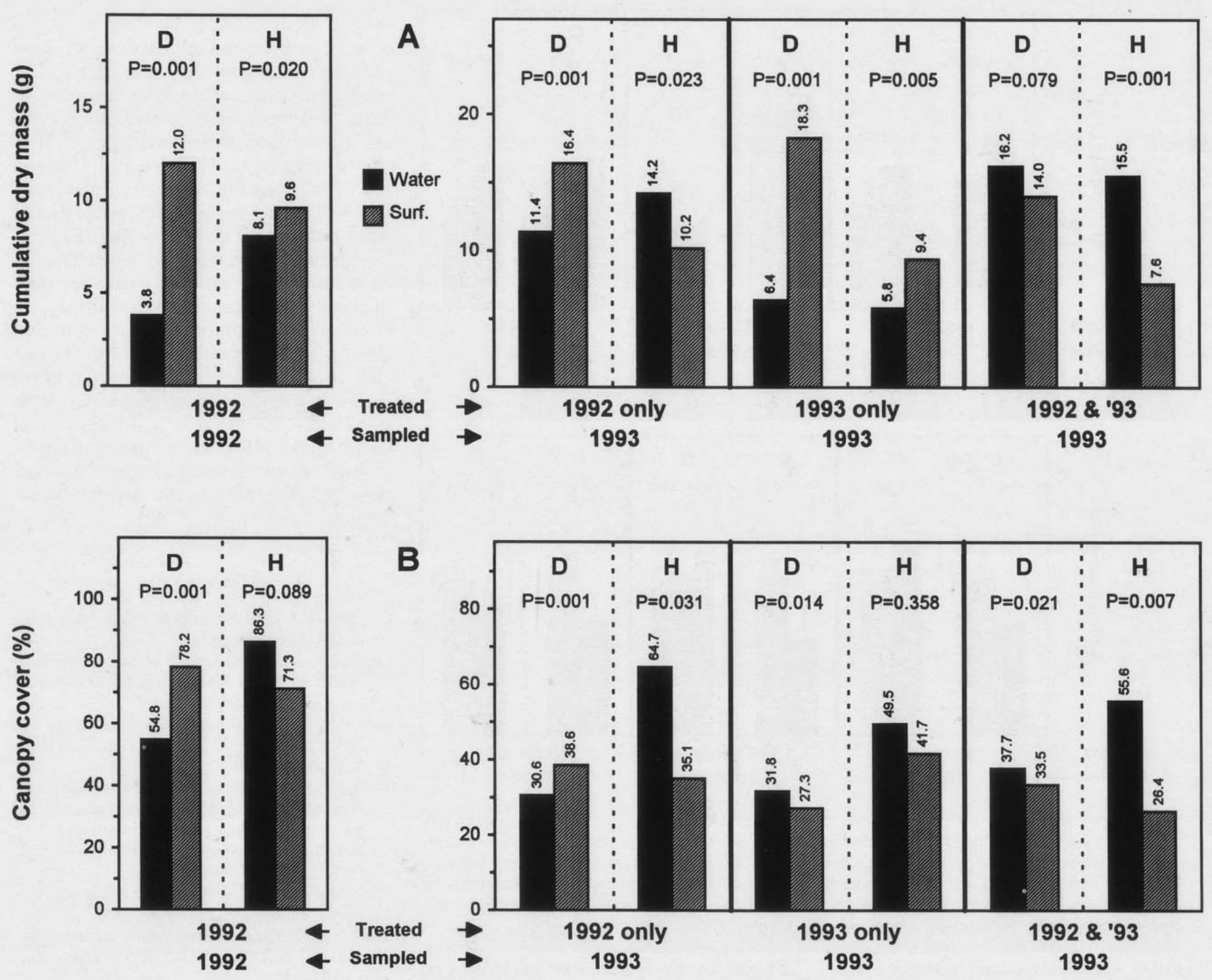

Fig. 5. Effects of surfactants on grass production (A) and canopy cover (B). Treatments were applied in either 1992, 1993, or in both years and were evaluated in 1992 or 1993. Typically there were no fungicide effects, fungicide by surfactant interactions, or differences between Silwet L-77 and Sylgard (Table 4), and hence the $P$ values represent the attained significance levels for the differences between the average of the two organosilicones and the water control. Analysis was performed separately for diseased $(\mathbf{D})$ and healthy $(\mathbf{H})$ plots.
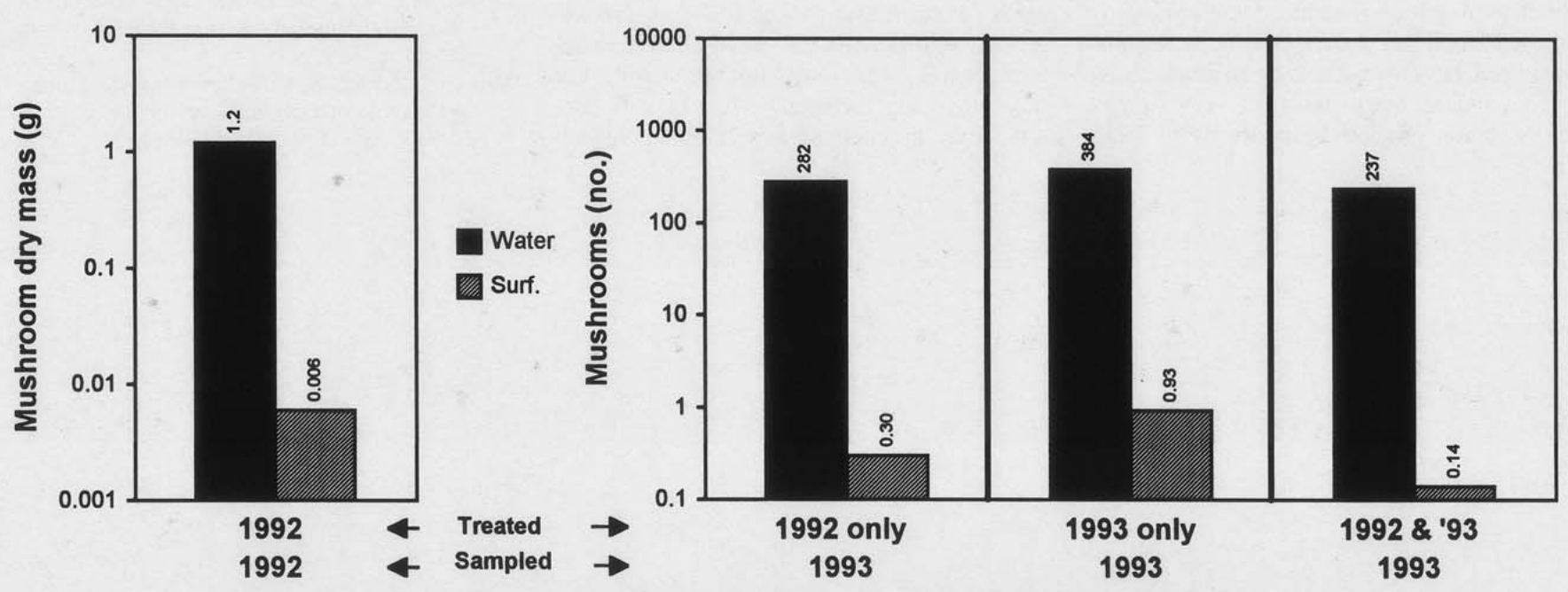

Fig. 6. Effects of surfactants on mushroom production. Treatments were applied in either 1992, 1993, or in both years and were evaluated in 1992 or 1993. Mushrooms were dried and weighed in 1992 and counted in 1993. Surfactant effects were averaged over fungicide treatments. Heterogeneity of variances, even following transformation, precluded statistical analysis. 
A

Water

Surf.

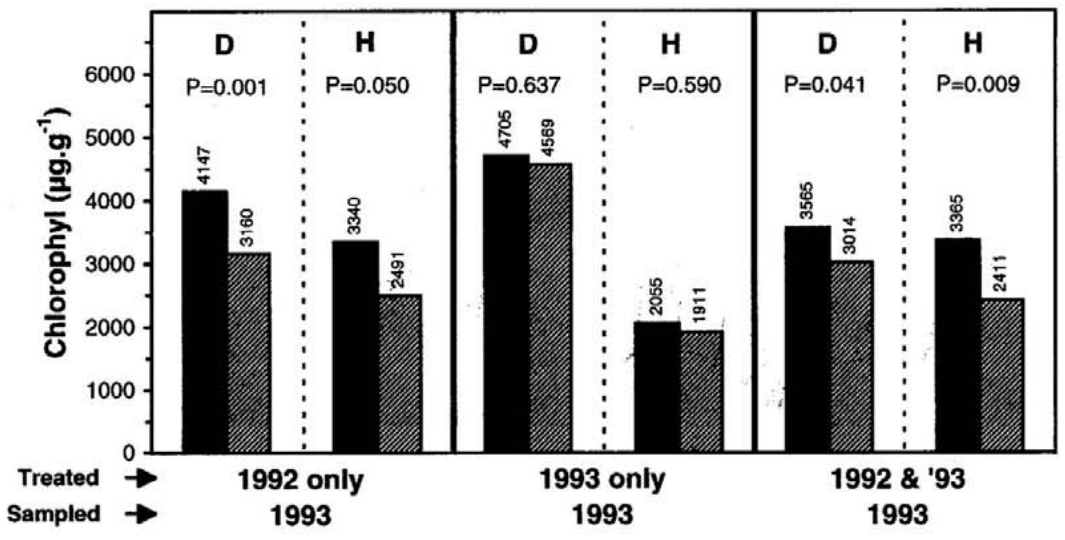

B

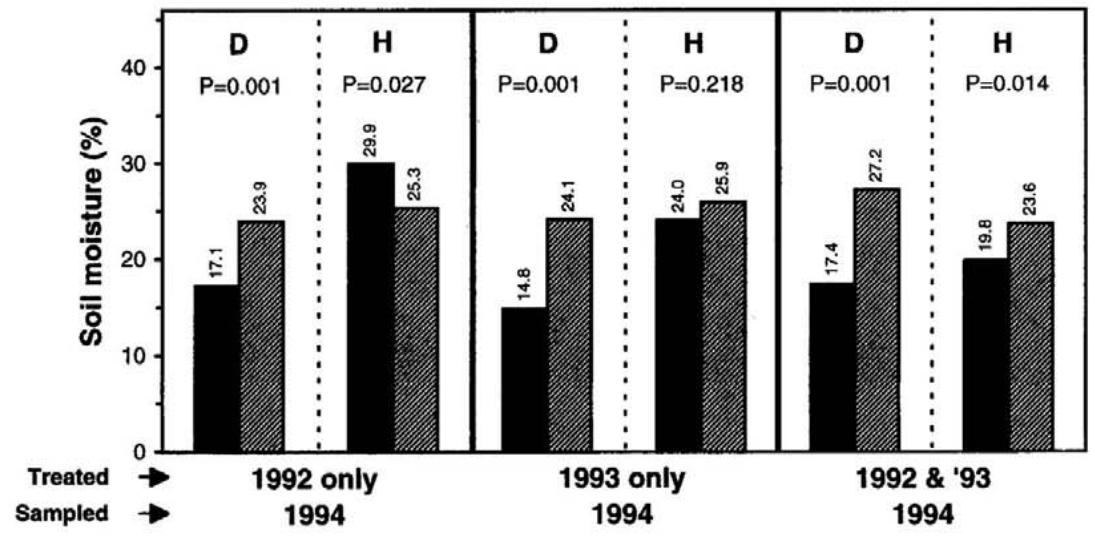

Fig. 7. Effects of surfactants on chlorophyll content (dry mass basis) (A) and soil moisture content (B). Treatments were applied in either 1992, 1993 or in both years and were evaluated in 1993 or 1994. Typically there were no fungicide effects, fungicide by surfactant interactions, or differences between Silwet L-77 and Sylgard (Table 5), and hence the $P$ values represent the attained significance levels for the differences between the average of the two organosilicones and the water control. Analysis was performed separately for diseased (D) and healthy (H) plots.

mine if the chemical treatments were effective in reducing the dark color associated with infestation. On plots treated in 1992 only and in both 1992 and 1993, the chlorophyll content of infested, surfactant-treated grass was very similar to that of untreated, healthy grass (Fig. 7A). However, the surfactant treatment reduced the chlorophyll content of healthy turf about as much as it reduced the content of infested turf. Thus, the organosilicones apparently were having an effect on turfgrass above and beyond that due to the effect on the fungus. Furthermore, in plots treated only in 1993, surfactant treatment did not affect chlorophyll content. In this instance the time between surfactant treatment and examination may have been inadequate to permit full expression of the effect.

Directly or indirectly, the organosilicones affected soil properties in both field and greenhouse experiments. In the greenhouse, the ability of surfactant-treated soil to absorb water was significantly increased relative to untreated soil, 6 months after treatment. The absence of any surfactant effect on bulk density in the greenhouse experiments suggests that the organosilicones increased the ability of water to move into soil but did not change soil structure or pore size. In the field, water content was measured in 1994, 2 years after the last treatment of plots treated only in 1992, and 1 year after the last treatment of plots treated either only in 1993 or in both 1992 and 1993. In all cases, the water content of infested soils was greater in surfactant-treated than in water-treated plots (Table 5B, Fig. 7B).

The original strategy was to combine domestic fungicides with surfactants for fairy ring control. Although chlorothalonil had some effect on mushroom production, its overall effect was much less than that of the surfactants. In conclusion, organosilicones by themselves, without additional fungicides, have considerable potential for the management of fairy ring. Because of the possibility of phytotoxicity, additional work is required to determine the optimum surfactant dose for disease control.

\section{Literature Cited}

Conover, W.J. 1980. Practical nonparametric statistics. Wiley, Toronto.

Littell, R.C., G.A. Milliken, W.W. Stroup, and R.D. Wolfinger. 1996. SAS system for mixed models. SAS Inst., Cary, N.C.

McKeague, J.A. 1976. Manual on soil sampling and methods of analysis. Soil Res. Inst., Can. Dept. Agr. Ottawa, Ont.

Nadeau, L.B.,P.V.Blenis, and N.R. Knowles. 1993. Potential of an organosilicone surfactant to improve soil wettability and ameliorate fairy ring symptoms caused by Marasmius oreades. Can. J. Plant Sci. 73:1189-1197.

SAS Institute. 1989. SAS/STAT user's guide, version 6, 4th ed. SAS Inst., Cary, N.C.

Shantz, 1917. Fungus fairy rings in eastern Colorado and their effect on vegetation. J. Agr. Res. 11:191-246.

Smith, J.D. 1978. Control of Marasmius oreades fairy rings: A review of methods and new approaches to their elimination. J. Sports Turf Res. Inst. 54:106-114.

Smith, J.D. 1980. Is biological control of Marasmius oreades fairy rings possible? Plant Dis. 64:348354.

Stokes, M.E., C.S. Davis, and G.G. Koch. 1995. Categorical data analysis using the SAS system. SAS Inst., Cary, N.C.

Vernon, L.P. 1960. Spectrophotometric determination of chlorophylls and pheophytins in plant extracts. Anal. Chem. 32:1144-1150. 